\title{
PROCESS LAYOUT PLANNING AND OPTIMISED PRODUCT RANGE SELECTION IN MANUFACTURE OF WOODEN CONSTRUCTION SETS
}

\author{
Mieczyslaw S. Siemiatkowski, , Mária Vargovskán
}

\begin{abstract}
This paper introduces a systematic deterministic framework for planning and the analysis of facility layouts aimed at manufacturing a variety of parts, being components of specific end products. The essence of the proposed approach lies in the decomposition of a traditional job-shop into layout modules of generic material flow patterns that inherently yields improved efficiency of the entire system. It entails the use of a relevant reasoning scheme based on production flow analysis and the method of hierarchical clustering of specified process routings for parts. The approach has been studied in the aspect of its application in an actual woodworking facility, dealing with fabrication of wooden toy sets. The respective workflows were subjected to the analysis in order to identify production bottlenecks using data derived from the real case study. As a result, the designated process layout alternatives have been evaluated in terms of assumed measures of the operational performance. An inseparable part of the research was exploring the capability for the optimum selection of a multi-part product mix, to be fabricated in defined time frames. In this regard, the usability as well as the computational efficacy of the integer linear programming modelling have been fully confirmed. The results gained show in particular that the suggested methodical scheme could be a useful tool in planning optimised manufacture of customised wood products of modular construction.
\end{abstract}

Keywords: Integer linear programming, manufacturing, near-optimal process layout, product-mix selection, wood products.

\section{INTRODUCTION}

Contemporary manufacturing is realised in dynamically changing environment with increased demand on customised high quality products, to be fabricated at the right time and in required quantities. Simultaneously, product development cycles have been significantly shortened while maintaining an acceptable level of the overall cost (Barni et al. 2017). Under the circumstance, manufacturing enterprises have to constantly adapt their structures and industrial practices to sustain the ability to cope with changes in product demand and variety (Nakkiew and Poolperm 2016) and reduced environmental impact (Esmaeilian et al. 2016). Striving for higher production efficiency have entailed the need for applying more efficient modular-type systems of specified material flow patterns, as implied by Stump and Badurdeen (2012). Material flow analysis (MFA), intended to its rationalization, has been for long among those measures, which inherently might be contributive to minimizing losses in the production process and the improvement of manufacturing system operation, thus lowering overall production cost. The analysis plays a crucial role in detecting potential bottlenecks in production and in searching for a more efficient process layout, characterized by the reduced negative impact of these bottlenecks on system performance (Thoews et al. 2008).

\footnotetext{
${ }^{1}$ Gdansk University of Technology, Mechanical Engineering Faculty, Dept. of Manufacturing and Production Engineering, Gdansk, Poland.

${ }^{2}$ Technical University in Zvolen, Faculty of Environmental and Manufacturing Technology, Dept. of Manufacturing and Automation Technology, Zvolen, Slovakia.

"Corresponding author: msiemiat@pg.edu.pl

Received: 04.12.2017 Accepted: 31.08.2018
} 
The important issue in manufacturing practice has also been making the adequate decisions regarding the optimal selection of product assortment and manufacturing the individual items in the right quantities in specified time horizons (Gould and Colwill 2015, Nyemba and Mbohwa 2017a). To a large extent, this can be referred to small and medium-sized woodworking plants, dealing with the fabrication of a wide range of multipart products, such as: indoor or outdoor furniture, toy kits, wooden utility ware, etc. (Nakkiew and Poolperm 2016, Krajcovicova 2011).

Wood is a natural raw material usually linked to comfort and a variety of its species have been used in toy industries for many years since it provides positive visual effects, and a comfortable tactile sensation directly related to the degree of elasticity (Friso et al. 2015). Particularly, quality hardwoods (coming from deciduous trees) remain the best choice for making toys, which are rated by manufacturers as educational (Ebner and Petutschnigg 2007). This is mostly due to their higher density, better wear resistance and good machinability as distinguished from the wood of conifers (Wood Handbook 2010). The research by Belleville et al. (2016) in particular confirmed that plantation-grown Australian hardwoods, like Eucalypts, can perform well during moulding, drilling or sanding processes when appropriate tools and parameters are selected. Hereby, they also showed a potential of these timber species as a resource for the manufacture of high quality furniture and furnishings.

Existing reports of adequate research work provide a number of both deterministic and simulation-based models of confirmed applicability to planning and optimization of process layouts in the area of discrete manufacturing (Esmaeilian et al. 2016). Regardless of the model type applied, the economic benefits resulting from its usage largely depend on the character of existing material flows and the capacities of available machine tools (Orlowski and Walichnowski 2013). To effectively solve the emerging problems in woodworking sector, Teischinger (2010) advocated the need for the development of new process technologies and relevant manufacturing strategies as parts of the knowledge-based production concept. In their review paper, Opacic and Sowlati (2017) highlighted the extensive applications and benefits of discrete-event simulation in the forest products sector, and particularly in bottleneck analyses and to assess different facility layouts and configurations. A comprehensive simulation-based approach to optimized planning of materials flow in a multi-product furniture assembling plant was reported by Nyemba and Mbohwa (2017a). An extended workflow analysis based on a stochastic data model was the core of their proposal. Alvarez and Vera (2014) presented the application of the robust optimization methodology to a sawmill planning problem that can deal with the uncertainty or variability factors in some of the input data. Moraga and Baesler (2001) utilised the concept of an integrated simulation modelling and optimisation, based on a genetic algorithms heuristic, in research of a remanufacturing radiata pine process on a production line of a Chilean regional timber plant. Longo et al. (2006) implemented genetic algorithms into the simulation model as generic objects. They were further used in searching for an optimal system configuration, characterized by minimum material handling cost in manufacturing wood products. Thoews et al. (2008) as well as Thomas et al. (2015) were also among those who applied simulation modelling for the improvement in productivity of respective sawmill workshops by the identification of related production bottlenecks. The latter authors in particular utilized the association of regression trees and neural networks to develop a reduced simulation model for extended work flow analysis in the sawmill facility. Rahman et al. (2014) reviewed the advances associated with the use of mathematical optimization techniques like linear and integer programming as well as artificial intelligence methods in combination with discrete event simulation, in order to solve issues related to logistics at sawmill yard operations.

Addressing the above mentioned problems, the main objective of this research is to provide a robust approach towards planning near-optimal woodworking facility layouts for manufacture of a multi-part product range. The optimality is understood as the operational efficiency which can be expressed by generated profits on sales, considering dynamic system working conditions.

\section{MATERIALS AND METHODS}

The framework introduced by Irani and Huang (2006), and suitable for planning modular layouts of multi-product custom manufacturing departments, has been adopted in this research work. Its application to facility layout planning and related analysis seems to be particularly well-founded under the circumstance of repetitive manufacturing a part mix of relatively high variety and in small quantities (Stump and Badurdeen 2012). 
So formulated research problem involves an extensive use of Material Flow Analysis (MFA) that is aimed at the evaluation and rationalisation of material flow in production (Gould and Colwill, 2015). Methodical schemes applied to solve for the intended manufacturing layouts assume the input data model related to process routings for parts of a given spectrum $\mathrm{P}=\left(\mathrm{p}_{1}, \ldots, \mathrm{p}_{\mathrm{n}}\right)$ that can be represented by $m$-dimensional vectors $x$, $=\left(x_{r l}, \ldots, x_{r m}\right)^{T}, x_{r} \in R^{m}, r=1,2, \ldots, n$, where: $m$ is the number of machines available in a definite facility. Most commonly, these vectors consist of binary values, indicating machines involved into fabrication of individual parts. Efficacious designing the modular type facility layouts, however, entails the need to determine the sequence of machines required in respective process plans (Yin and Yasuda 2006, Goyal et al. 2013). Hence in this study, individual operation sequences are denoted numerically by machine numbers that occur in corresponding part routings. This approach is also in line with the scheme followed by Nyemba and Mbohwa (2017b), where the process flows of a furniture manufacturing plant were mapped and then optimized considering the transportation distances and interactions among workstations. As a result, the decomposition of the existing facility into linked production segments (or partial cells) of specific part flow patterns could be carried out, based on a comparative analysis and evaluation of part operation sequences given as character strings (Siemiatkowski 2010). Moreover, linear process plans could be introduced in layout designs with an acceptable level of machine duplication to avoid possible parts backtracking (Longo et al. 2006).

\section{Manufacturing planning schema and its instance application in a woodworking facility}

The heuristic procedure for planning adequate facility layouts, being a slight modification of its earlier version reported in Siemiatkowski (2010), is outlined in Table 1.

Table 1: Solution procedure for planning a modular facility layout based on MFA analysis.

\begin{tabular}{|l|l|l|}
\hline 1 & Material flow analysis in a facility aimed at mapping part routings as machine sequences \\
\hline 2 & Identification of common substrings, if any, between all pairs of part routings \\
\hline 3 & $\begin{array}{l}\text { Clustering common substrings into groups using the average linkage clustering algorithm (ALCA) rule } \\
\text { and the percent disagreement distance (dissimilarity) metric, and next generating layout modules from } \\
\text { extracted clusters }\end{array}$ \\
\hline 4 & $\begin{array}{l}\text { Generation of flow-type layout modules in terms of definite machine sequences to represent each group } \\
\text { of common substrings }\end{array}$ \\
\hline 5 & \begin{tabular}{l} 
Inclusion of residual machines (if any) and respective modification of a generated layout configuration \\
\hline \multirow{2}{*}{6}
\end{tabular} & $\begin{array}{l}\text { Generating workflow strategies (job sequencing by FIFO rule) to identify possible production } \\
\text { bottlenecks; estimating system capacity requirements and allocation of duplicate machines to layout } \\
\text { modules (Equation 1-3) }\end{array}$ \\
\cline { 2 - 4 } & 7 & Generating final design solution of a modular layout configuration with relevant material flow pattern \\
\hline
\end{tabular}

A relevant MFA analysis is underlying the suggested procedure (step 1) that has been complemented by the activities of the consecutive steps $2 \div 5$. As shown below, those steps are associated with a comparative analysis and evaluation of part operation sequences and their hierarchical clustering based on a given distance metric. To allow the envisaged clustering task, two substring types of in operation sequences were distinguished, as given in Irani and Huang (2006). Those are: a substring of consecutive operations that is common to at least two operation sequences, termed further as a common substring, and the remainder substring(s) of operations in a sequence, after the common substring(s) are extracted from it. The latter ones are termed as residual substrings, respectively.

This research involves the application of the developed heuristic procedure to extended analysis of a production process in an actual woodworking facility with the aim of finding a process layout of improved performance. The real case of a production department at the manufacturer of wooden toy sets (Kusing Trade, s.r.o., Slovakia) has been brought under study. It is designated to multi-assortment parts fabrication, made of the European beech species (Fagus Sylvatica), as the components of definite construction sets (Figure 1). Some of the wooden constructions that can be assembled of components available in an exemplary toy set and offered by the manufacturer, are depicted in Figure 2. 


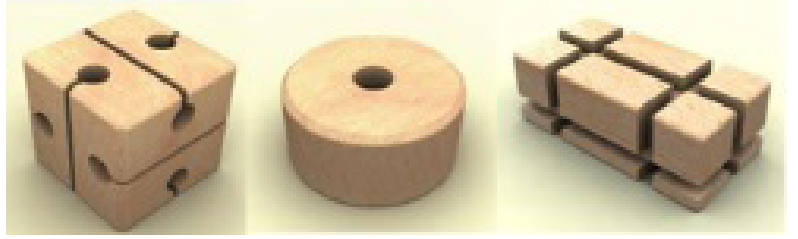

Figure 1: Sample elements of construction sets VEVA Product Slovakia (a business member of Montessori Europe), produced by Kusing Trade, s.r.o.

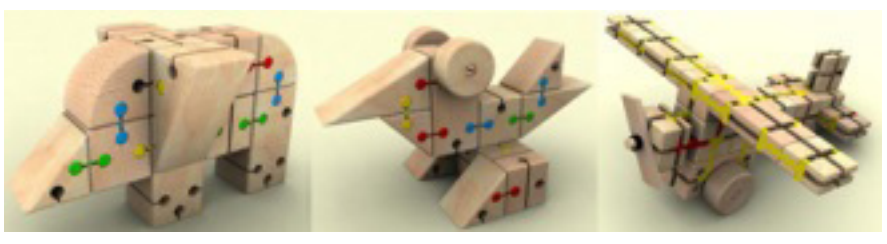

Figure 2: Sample multi-element wooden constructions, assembled of components available in a definite toy set, offered by the manufacturer.

The actual system incorporated 9 different woodworking machines, termed further, as: $\mathrm{M}_{1}$ - edging saw machine, $M_{2}$ - cross-cut saw, $M_{3}$ - drilling machine, $M_{4}$ - slotting machine, $M_{5}$ - frame saw, $M_{6}-$ pin-turning lathe, $\mathrm{M}_{7}$ - turning lathe, $\mathrm{M}_{8}$ - band saw, and $\mathrm{M}_{9}$ - drum sander. By our discernment, it was originally operated as a traditional job shop at machines arrangement, as shown in Figure 3. Material handling tasks were accomplished in it using a hand-operated pallet truck (called TR).

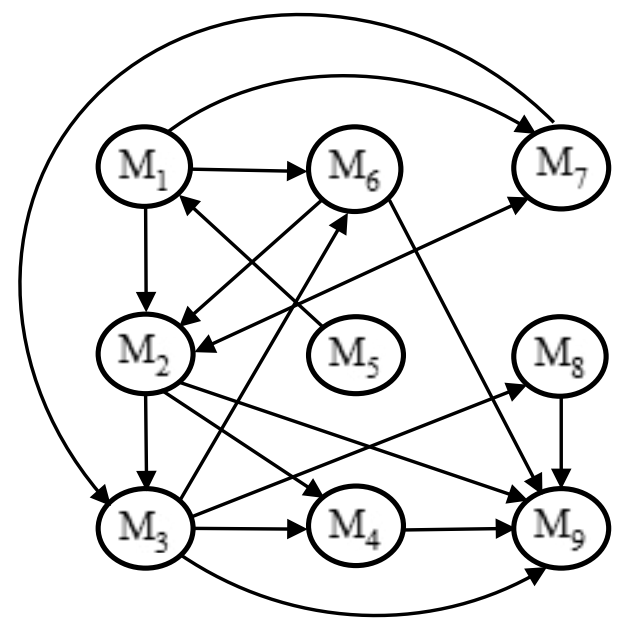

Figure 3: The actual facility configuration (prior to the application of MFA analysis) and related material flow (indicated by arrows); $\mathrm{M}_{1} \div \mathrm{M}_{9}-$ available machine resources.

Material flow identification in the facility was needed: first to gain an understanding of its setup and operation, and then to develop a conceptual model of its decomposition into layout modules. The relevant spectrum of products manufactured in the facility was determined. It included 31 different part types (P1, P2, .., P31) which might occur as items of 11 various construction sets. The appropriate routings for parts have been mapped as machine sequences. Moreover parts that followed same routings were classified into 9 specific groups (Table 2). 
Table 2: Distribution of part types to groups and related machine sequences.

\begin{tabular}{|l|l|l|}
\hline Part group no. & Group composition & Machine sequence \\
\hline Gr1 & $\{\mathrm{P} 1, \mathrm{P} 2, \mathrm{P} 3, \mathrm{P} 4, \mathrm{P} 5, \mathrm{P} 6, \mathrm{P} 7, \mathrm{P} 8, \mathrm{P} 12, \mathrm{P} 13, \mathrm{P} 14, \mathrm{P} 15, \mathrm{P} 17\}$ & $\mathrm{M}_{1} \rightarrow \mathrm{M}_{2} \rightarrow \mathrm{M}_{3} \rightarrow \mathrm{M}_{4} \rightarrow \mathrm{M}_{9}$ \\
\hline Gr2 & $\{\mathrm{P} 9\}$ & $\mathrm{M}_{5} \rightarrow \mathrm{M}_{1} \rightarrow \mathrm{M}_{6} \rightarrow \mathrm{M}_{2} \rightarrow \mathrm{M}_{3} \rightarrow \mathrm{M}_{9}$ \\
\hline Gr3 & $\{\mathrm{P} 10\}$ & $\mathrm{M}_{1} \rightarrow \mathrm{M}_{2} \rightarrow \mathrm{M}_{7} \rightarrow \mathrm{M}_{3} \rightarrow \mathrm{M}_{4} \rightarrow \mathrm{M}_{9}$ \\
\hline Gr4 & $\{\mathrm{P} 11, \mathrm{P} 27\}$ & $\mathrm{M}_{1} \rightarrow \mathrm{M}_{7} \rightarrow \mathrm{M}_{2} \rightarrow \mathrm{M}_{4} \rightarrow \mathrm{M}_{9}$ \\
\hline Gr5 & $\{\mathrm{P} 16\}$ & $\mathrm{M}_{1} \rightarrow \mathrm{M}_{2} \rightarrow \mathrm{M}_{3} \rightarrow \mathrm{M}_{6} \rightarrow \mathrm{M}_{9}$ \\
\hline Gr6 & $\{\mathrm{P} 18, \mathrm{P} 19, \mathrm{P} 20, \mathrm{P} 21, \mathrm{P} 22, \mathrm{P} 23, \mathrm{P} 24, \mathrm{P} 25, \mathrm{P} 26\}$ & $\mathrm{M}_{1} \rightarrow \mathrm{M}_{2} \rightarrow \mathrm{M}_{3} \rightarrow \mathrm{M}_{8} \rightarrow \mathrm{M}_{9}$ \\
\hline Gr7 & $\{\mathrm{P} 28\}$ & $\mathrm{M}_{1} \rightarrow \mathrm{M}_{7} \rightarrow \mathrm{M}_{2} \rightarrow \mathrm{M}_{9}$ \\
\hline Gr8 & $\{\mathrm{P} 29\}$ & $\mathrm{M}_{1} \rightarrow \mathrm{M}_{6} \rightarrow \mathrm{M}_{2} \rightarrow \mathrm{M}_{3} \rightarrow \mathrm{M}_{4} \rightarrow \mathrm{M}_{9}$ \\
\hline Gr9 & $\{\mathrm{P} 30, \mathrm{P} 31\}$ & $\mathrm{M}_{1} \rightarrow \mathrm{M}_{2} \rightarrow \mathrm{M}_{4} \rightarrow \mathrm{M}_{9}$ \\
\hline
\end{tabular}

where: P1, P2, .., P31 - part types manufactured in the facility.

According to the established procedure (step 2), the needed identification of common substrings of machines between all pairs of operation sequences for part groups was made next. Given the routing data shown in Table 2, the common substrings of machines were discerned for the analysed case as well as the respective number of their occurrence (Table 3). A relevant applet application for finding common substrings in two operation sequences can be found among other in the reported paper of Irani and Huang (2006).

Table 3: Unique common substrings in the operation (machine) sequences for part groups.

\begin{tabular}{|l|l|l|}
\hline Substring no. & Common substring as a machine sequence & No. of occurrence \\
\hline St1 & $M_{1} \rightarrow M_{2}$ & 7 \\
\hline St2 & $M_{1} \rightarrow M_{2} \rightarrow M_{3}$ & 3 \\
\hline St3 & $M_{1} \rightarrow M_{6} \rightarrow M_{2} \rightarrow M_{3}$ & 1 \\
\hline St4 & $M_{1} \rightarrow M_{7} \rightarrow M_{2}$ & 1 \\
\hline St5 & $M_{2} \rightarrow M_{3}$ & 5 \\
\hline St6 & $M_{2} \rightarrow M_{3} \rightarrow M_{4} \rightarrow M_{9}$ & 1 \\
\hline St7 & $M_{2} \rightarrow M_{4} \rightarrow M_{9}$ & 1 \\
\hline St8 & $M_{3} \rightarrow M_{4} \rightarrow M_{9}$ & 2 \\
\hline St9 & $M_{4} \rightarrow M_{9}$ & 6 \\
\hline
\end{tabular}

The common machine sequences, found in the routings for part groups, were subjected to cluster analysis next (step 3), that was performed using the appropriate module of data analysis system (Dell Statistica Software, 2016). For that purpose, the agglomerative hierarchical clustering method with the unweighted pairgroup average linkage algorithm (ALCA) was adopted. At the initial stage of related analysis in particular, the pairwise comparisons of the common substrings in terms of dissimilarity have been made, using the percent disagreement metric which is available in the aforementioned software module. Under such assumptions, the results of clustering could be provided in the form of a generated dendrogram (an inverted tree structure), as shown in Figure 4. Two clusters were extracted from the given data (Figure 4) before reaching the threshold value of the computed distance measure (as indicated with the bold dashed line), which terminated the action of the iterative algorithm. Based on the clustering results, and consistently with these in-prior studies on discrete manufacturing facility planning, two basic layout modules with specific material flow patterns could be formed. Those are depicted in terms of machine sequences, conveyed as directed acyclic graphs (Table 4), that exhibit no parts backtracking, correspondingly to the flow type production pattern (Siemiatkowski 2010). The inclusion of the residual machines was also due to be considered in this layout study (step 5 of the outlined procedure) to consistently develop the desired modular facility configuration. 


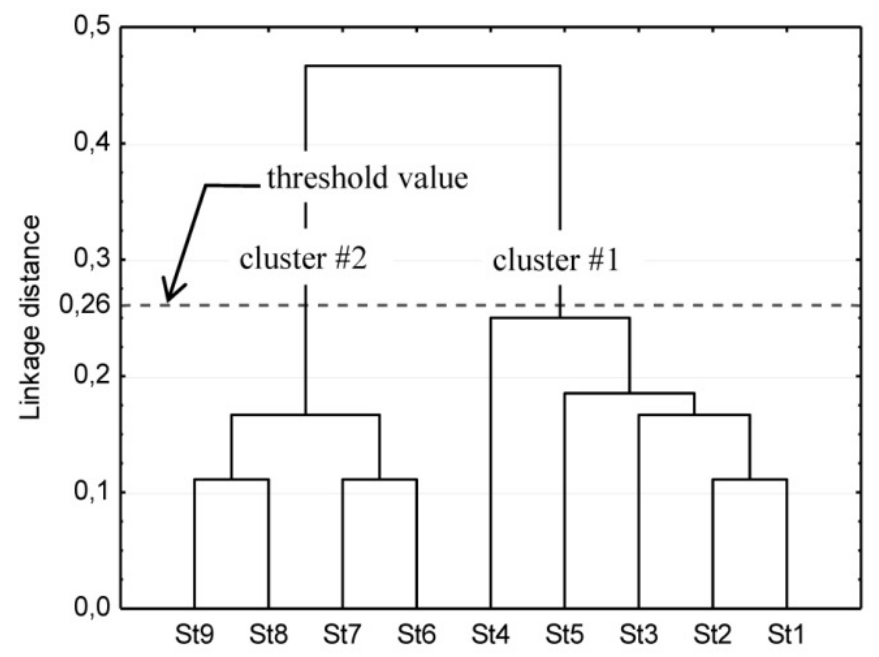

Figure 4: Dendrogram of the ALCA analysis with grouping the common substrings by the percent disagreement metric.

Table 4: Layout modules generated from clusters in Figure 4 (step 4 of the procedure in Table 1).

\begin{tabular}{|l|l|l|}
\hline Module no. & Cluster of common substrings & Directed acyclic graph for the layout module \\
\hline Module 1 & St1, St2, St3, St4, St5 \\
\hline Module 2 & St6, St7, St8, St9
\end{tabular}

\section{Studying workflows in a definite facility layout}

Apart from the operation sequences, the knowledge of processing times for individual parts and detailed structure (a bill of materials) of each multi-part product were indispensable to perform a complete quantitative analysis of material flow in the woodworking facility. Process and machine parameters, such as the preliminary data, were assumed based on the actual process plans of the mentioned manufacturer. For brevity, the unit processing times for individual part components $\mathrm{P}_{\mathrm{k}}, k=1, \ldots, \mathrm{c}$, manufactured with the use of available machines $\mathrm{M}_{\mathrm{i}}, i=1, \ldots, \mathrm{m}$, are compiled respectively in the form of a matrix $T=\left(t_{i k}\right)_{m x c}$, in Table 5.

The number of part components involved in definite construction sets $\mathrm{S}_{\mathrm{j}}, j=1, \ldots, \mathrm{s}$, were in turn given in Table 6, based on which the corresponding input matrix $Q=\left(q_{k j}\right)_{c x s}$ was created. 
Table 5: Matrix $\mathrm{T}=\left(\mathrm{t}_{i k}\right)_{m x_{c}}$ of operation times ( $\mathrm{min}$ ) in manufacturing the individual part components using available woodworking machine tools.

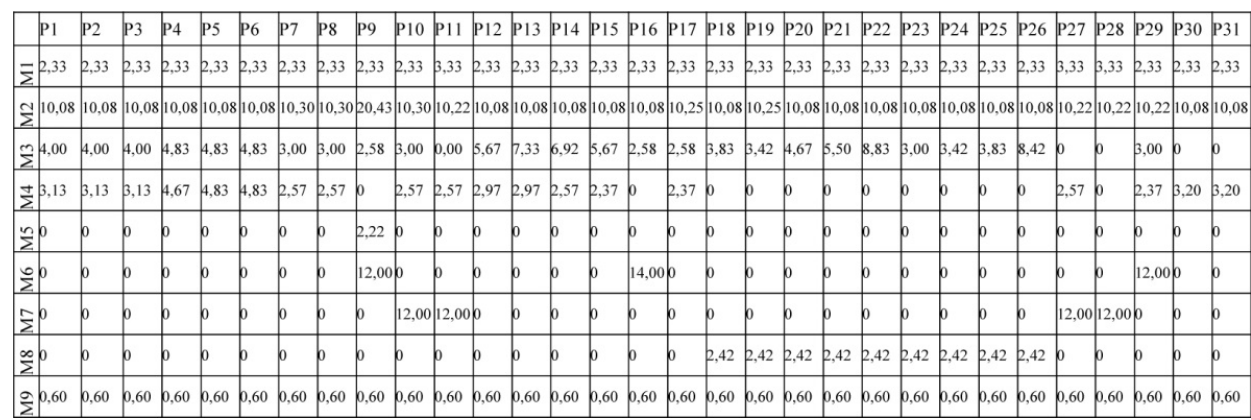

Table 6: The number of individual components occurred in definite products (construction kits), along with total number of components present in all product items.

\begin{tabular}{|c|c|c|c|c|c|c|c|c|c|c|c|c|c|c|c|c|c|c|c|c|c|c|c|c|c|c|c|c|c|c|}
\hline P1 & P2 & P3 & P4 & P5 & P6 & P7 & P8 & P9 & P10 & P11 & P12 & P13 & P14 & P15 & P16 & P17 & P18 & P19 & $\mathrm{P} 20$ & P21 & P22 & P23 & P24 & P25 & P26 & P27 & P28 & P29 & P30 & P31 \\
\hline $\bar{n} 0$ & 1 & 0 & 0 & 1 & 0 & | & 0 & 1 & 4 & 2 & 0 & 0 & 0 & 0 & 0 & 0 & 0 & 0 & 0 & 0 & 0 & 0 & p & 0 & 0 & 0 & 0 & 0 & 0 & 0 \\
\hline$\sigma^{3}$ & 1 & 1 & 0 & 2 & 0 & 4 & 2 & 2 & 4 & 2 & 0 & 0 & 0 & 0 & p & 0 & 0 & 0 & 0 & 0 & 0 & 0 & 0 & 0 & 0 & 0 & 0 & 0 & 0 & 0 \\
\hline$\tilde{n}^{4}$ & 4 & 4 & 1 & 2 & 3 & 4 & 4 & 4 & 4 & 2 & 0 & 0 & 0 & 0 & p & 0 & 0 & 0 & 0 & 0 & 0 & 0 & p & 0 & 0 & 0 & 0 & 0 & 0 & 0 \\
\hline 412 & 12 & 12 & 8 & 12 & 12 & 12 & 12 & 12 & 12 & 4 & 0 & 0 & 0 & 0 & p & 0 & 0 & 0 & 0 & 0 & 0 & 0 & p & 0 & 0 & 0 & 0 & 0 & 0 & 0 \\
\hline$\approx^{18}$ & 18 & 16 & 12 & 18 & 18 & 16 & 16 & 16 & 20 & 12 & 0 & 0 & 0 & 0 & 0 & 0 & 0 & 0 & 0 & 0 & 0 & 0 & $p$ & 0 & 0 & 0 & 0 & 0 & 0 & 0 \\
\hline$\overbrace{}^{24}$ & 24 & 24 & 16 & 24 & 24 & 24 & 24 & 24 & 24 & 8 & 0 & 0 & 0 & 0 & 0 & 0 & 0 & 0 & 0 & 0 & 0 & 0 & 0 & 0 & 0 & 0 & 0 & 0 & 0 & 0 \\
\hline$\hat{n}^{0}$ & 0 & 0 & 0 & 0 & 0 & 0 & 0 & 0 & 0 & 0 & 1 & 1 & 2 & 1 & 3 & 4 & 2 & 0 & 2 & 0 & 0 & 4 & T & 0 & 0 & 2 & 20 & 0 & 0 & 0 \\
\hline$\infty^{0}$ & 0 & 0 & 0 & 0 & 0 & 0 & 0 & 0 & 0 & 0 & 6 & 7 & 4 & 4 & 6 & 8 & 4 & 4 & 4 & 4 & 6 & 6 & 4 & 2 & 1 & 4 & 50 & 1 & 0 & 0 \\
\hline$\dot{s}^{0}$ & 0 & 0 & 0 & 0 & 0 & 0 & 0 & 0 & 0 & 0 & 0 & 0 & 0 & 0 & 0 & 0 & 0 & 0 & 0 & 0 & 0 & 0 & p & 0 & 0 & 0 & 0 & 0 & 42 & 2 \\
\hline$\frac{0}{n} 0$ & 0 & 0 & 0 & 0 & 0 & 0 & 0 & 0 & 0 & 0 & 0 & 0 & 0 & 0 & 0 & 0 & 0 & 0 & 0 & 0 & 0 & 0 & $p$ & 0 & 0 & 0 & 0 & 0 & 84 & 4 \\
\hline $\bar{n} 0$ & 0 & 0 & 0 & 0 & 0 & 0 & 0 & 0 & 0 & 0 & 0 & 0 & 0 & 0 & 0 & 0 & 0 & 0 & 0 & 0 & 0 & 0 & p & 0 & 0 & 0 & 0 & 0 & 168 & 12 \\
\hline 61 & 60 & 57 & 37 & 59 & 57 & 61 & 58 & 59 & 68 & 30 & 7 & 8 & 6 & 5 & 9 & 12 & 6 & 4 & 6 & 4 & 6 & 10 & 5 & 2 & 1 & 6 & 70 & 1 & 294 & 18 \\
\hline
\end{tabular}

As a result, the matrix of work time consumed by each machine involved in manufacture of individual product items (construction sets) could be computed as a product of the input matrices, as follows:

$W=T Q$. Consequently, its entries are determined by the equation 1 :

$$
w_{i j}=\sum_{k=1}^{c} t_{i k} q_{k j}
$$

where: $i=1,2, \ldots, \mathrm{m} ; j=1,2, \ldots, \mathrm{s} ;$ and $\mathrm{s}-$ total number of construction sets produced.

With regard to the illustrative case study the results of these calculation are shown in Table 7. 
Table 7: Workload of individual machines utilised in manufacturing specific products (construction sets) correspondingly to the matrix $\mathrm{W}_{\mathrm{m} \times \mathrm{s}}$ of times (min).

\begin{tabular}{|l|l|l|l|l|l|l|l|l|l|l|l|}
\hline MT $\backslash$ set & S1 & S2 & S3 & S4 & S5 & S6 & S7 & S8 & S9 & S10 & S11 \\
\hline M1 & 25,33 & 51,00 & 86,00 & 284,00 & 432,00 & 568,00 & 122,33 & 345,67 & 102,67 & 205,33 & 420,00 \\
\hline M2 & 112,53 & 234,88 & 407,27 & 1342,53 & 1993,47 & 2685,07 & 437,18 & 1269,75 & 443,67 & 887,33 & 1815,00 \\
\hline M3 & 26,42 & 64,83 & 123,33 & 437,67 & 637,33 & 875,33 & 83,00 & 345,25 & 0 & 0 & 0 \\
\hline M4 & 25,93 & 56,13 & 102,37 & 368,80 & 557,20 & 737,60 & 28,03 & 89,87 & 140,80 & 281,60 & 576,00 \\
\hline M5 & 2,22 & 4,43 & 8,87 & 26,60 & 35,47 & 53,20 & 0 & 0 & 0 & 0 & 0 \\
\hline M6 & 12,00 & 24,00 & 48,00 & 144,00 & 192,00 & 288,00 & 42,00 & 96,00 & 0 & 0 & 0 \\
\hline M7 & 72,00 & 72,00 & 72,00 & 192,00 & 384,00 & 384,00 & 264,00 & 648,00 & 0 & 0 & 0 \\
\hline M8 & 0 & 0 & 0 & 0 & 0 & 0 & 21,75 & 84,58 & 0 & 0 & 0 \\
\hline M9 & 6,00 & 12,60 & 21,60 & 72,00 & 108,00 & 144,00 & 25,80 & 75,00 & 26,40 & 52,80 & 108,00 \\
\hline
\end{tabular}

It has been assumed that quality inspection is accomplished at different places of the system under study, and namely: (i) at input store on arrival of raw material units, (ii) at intermediate stages of the manufacturing process, (iii) at output store before expediting ready part components to marking and packaging department. While parts manufacture in particular, this task is realised as the inspection for product attributes using visual control, the means of manual measurements and gaging. Therein, the times of those activities were included into the unit operation time (given in Table 5). According to the findings of the actual process fraction defect rate can be estimated as less than $1,5 \%$, which can recognised as relatively low for that kind of work material and applied technology. The rate can be understood as the probability of producing a defective piece each cycle of machine operation (Siemiatkowski and Przybylski 2006). Nevertheless, the possibility for the occurrence of non-conforming part units has been neglected in the planning scheme of process alternatives, as this scheme assumes the use of a deterministic data model. This entails omitting the effect of fraction defect rate on performance aspects of production in generated system layouts. Considering the above, related workflows in the custom facility were studied using an academic version of the commercial software of Preactor Intl. (Preactor 9.5 APS $\left.^{\circledR}, 2009\right)$. The above activities were appropriately addressed in step 6 of the developed framework (Table1). Using the functionalities of the production scheduling tool, sequencing adequate process tasks was realised on a basis of the First-Come-First-Serve (FCFS) strategy.

To determine the feasibility for duplicating machines, because of production bottlenecks encountered in the layout modules, the total available capacity was computed by the equation 2 (Siemiatkowski 2010):

$$
F_{i}=\Delta U_{i} T_{0}
$$

where:

$F_{i}$ - total available loading capacity per machine of type $j$, in ( $\mathrm{min}$ ); $\Delta U_{j}$ - the utilisation factor of machine type $j$ (assumed mostly within the range of $0,75 \div 0,85) ; T_{o}$ - duration of the production period under consideration, (min).

Then, the number of machines required (machine duplicates of type $i$ ) could be determined by the equation 3:

$$
\forall i=1, \ldots, m \quad M_{i}=\operatorname{entier}\left(\sum_{j=1}^{s} \frac{w_{i j}}{F_{i}}+0,99999\right)
$$

with: $w_{i j}$ - workload of machine $i$ involved in machining components of a construction kit $\mathrm{S}_{j}(\mathrm{~min})$; $s$ - total number of operations assigned to machine of type $i$.

\section{Mathematical model for optimum product-mix selection}

The problem of optimum multi-part product range selection, raised in this paper, was formulated as an integer linear programming (ILP) model (Sultan 1993), with the objective function aimed at the maximising 
the total value of monthly profit, as equation 4 (Krajcovicova 2011):

$$
P x \rightarrow \max
$$

where:, $P=\left(P_{j}\right)_{1 x s}$ therein $p_{j}$ is the unitary profit on sales of product item $j$ (see Table 8 for the values appropriate to the case studied), and $x=\left(x_{j}\right)_{1 x s}$ - vector of the realized production program (spectrum of products), with the entries $x_{j}$ denoting the production quantity of a particular set $\mathrm{S}_{j}$;

subject to relevant linear-type inequality constraints, such as equation 5 :

$$
W x \leq A T, \mathrm{x} \geq 0 \ldots
$$

where: $A T=\left(a t_{i}\right)_{1 x m}$ - vector of available working time for each machine, in min/month, $W=\left(w_{i j}\right)_{m x s}$ - matrix of times consumed by each machine involved in manufacturing an individual product item.

Table 8: Generated profit on sales of offered product items (wooden construction sets).

\begin{tabular}{|l|l|l|l|l|l|l|l|l|l|l|l|}
\hline Construction set & S1 & S2 & S3 & S4 & S5 & S6 & S7 & S8 & S9 & S10 & S11 \\
\hline Unitary profit in $€$ & 11,90 & 19,04 & 35,70 & 88,06 & 97,58 & 133,28 & 15,00 & 25,00 & 35,00 & 60,00 & 100,00 \\
\hline
\end{tabular}

Irrespective of those already mentioned, definite constraints can be formulated with regard to the production quantity (volume) of particular product items. Those additional restrictions are formally defined in the form of inequalities (or equations), as equation 6:

$$
\exists S_{j}, j=1,2, \ldots, s, x_{j} \leq V\left(\text { or }: x_{j}=V\right)
$$

where: $\mathrm{V}$ denotes the assumed limit value for number of given product types to be produced.

The rationale for establishing the constraints of such a kind was inevitably the need for rapid market responsiveness, under dynamic conditions of the manufacturing system operation.

In this study, the optimisation task has been formulated as integer linear programming problem and solved by the simplex procedure. The solution method was routinely utilised by the authors within the IBM ILOG ${ }^{\mathbb{R}}$ CPLEX $^{\circledR} 2016$ optimisation package in the version for academics.

\section{RESULTS AND DISCUSSION}

As a result, the final solution of a modular layout design has been generated (step 7 of the applied procedure), as depicted in Figure 5. The solution gained is further referred to as the baseline layout configuration. 


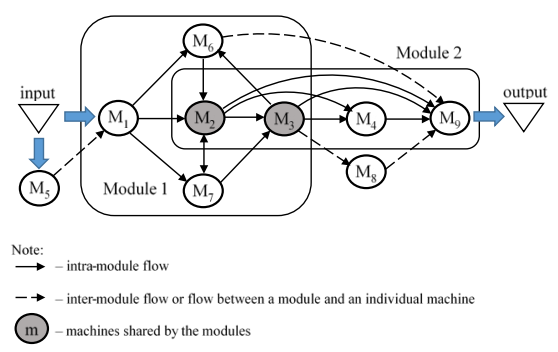

Figure 5: Network representation of a baseline facility layout under study with related material flow.

As it could be noticed, even based on cursory observations of production lead times at the manufacturer's, the postulated structural change of the original job-shop facility into the modular type process layout has significantly contributed to the reduction of the expenditure on material transport activities. Hence, in generating the respective workflows, the material transportation times between particular machines could be neglected, since by estimates their values amounted to less than $0,15 \mathrm{~min}$. In contrast, transportation times of material (for definite part batches) from input store for first machining operation, and the finished parts to the output store were assumed to be 0,3 min.

First, operational schedules were generated with regard to the baseline process layout and visualized in the form of Gantt charts, and then comparatively analysed in terms of standard quantitative parameters, such as: make span, average flow time for product batches and machine resource utilisation. Based on the workflow analysis, it was noted that for the baseline configuration, the cross-cut saw (machine $\mathrm{M}_{2}$ ) was always found as a process bottleneck, regardless of the composition of the production program. This was due to the longest cycle time for that machine as well as its use in processing all parts of the production spectrum (Table 5). The relatively low cost of the cross-cut saw (amounted to US\$11,500) and the possibility for rapid return on this investment, justified the introduction of a second machine of this type. It was found, however, that duplication of that machine did not cause the bottleneck to shift to another workstation located in the facility. Correspondingly with the manufacturer's focus on the maximum diversification of the its market offer, the production flow was further studied by the scenario that assumed parts manufacture in the quantities required for the realization of the complete product spectrum (i.e. one item of each kind of toy sets). Accordingly, the aforementioned routines in production flow, inherent to the two tested process layouts, can be traced back in Figure 6 .

Through adequate analysis of the deterministic model considered, the important measures for assessing the system performance could be calculated. Thus, the make span for the baseline system layout was found to be $211 \mathrm{~h}: 57 \mathrm{~min}$, with $93,5 \%$ utilization of the bottleneck machine, whilst for the scenario with doubled $\mathrm{M}_{2}$ machine it decreased significantly to $117 \mathrm{~h}: 44$ min with 88,9\% utilization of $\mathrm{M}_{2}$ machines on average (in deterministic type models, commonly termed as servers of a bottleneck station). For the former case of process layout, the average machine utilization amounted to $19,4 \%$, while for the latter it was already at $33,2 \%$. Solving the formulated linear programming model allowed to conclude that for process layout with single $\mathrm{M}_{2}$ machine the optimum selection for the product mix was to manufacture exclusively the S1 toy sets to maximise the value of the objective function. Thus, under conditions of single-shift mode of system operation, 85 pieces of those sets could be fabricated within a period of a month (for simplicity, equivalent to 160 working hours), allowing a maximum monthly profit of US\$ 1,163,22.

Subsequently, the model solutions for the scenario with doubled M2 were generated and investigated with same conditions of system operation, and under limitations imposed in regard to the production quantity of specific product items. Generated solutions for optimal assortment composition of manufactured sets, along with the monthly profit earned are compiled in Table 9, respectively. 


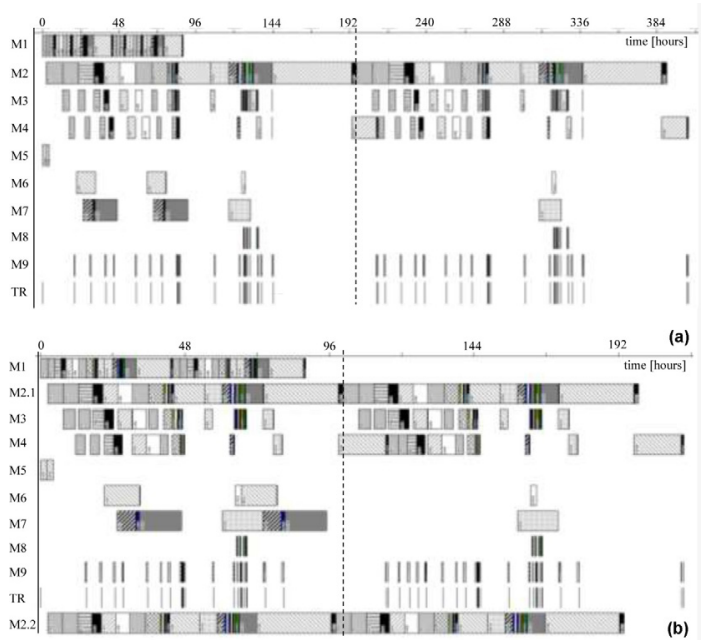

Figure 6: Gantt chart of operational schedule solution for the baseline system layout (scenario), i.e. with single machine $\mathrm{M}_{2}$, disclosed as a bottleneck (a) and for process layout with duplicated machine $\mathrm{M}_{2}$ (b); the bold dashed lines show the end of the first repetition and the start of the second repetition of the $\mathrm{M}_{2}$ (a bottleneck machine) production cycle, each one associated with the realisation of all assigned process operations for complete product spectrum.

It was noticeable that the optimal assortment composition, possible to be found, is highly determined by is highly determined by the established limits of production quantity of particular product items. Moreover, wider diversification of product assortment required, as a rule, the determination of more limits in the ILP model, being in the line with the formal notation (6) as well as making adequate changes of those constraints in shorter time intervals.

Table 9: Generated exemplary solutions for optimal assortment selection of manufactured toy sets, for the scenario with duplicated machine $\mathrm{M}_{2}$, and established product and process limitations.

\begin{tabular}{|l|l|l|}
\hline $\begin{array}{l}\text { Limitations on production quantity } \\
\text { of specific products (exemplary set- } \\
\text { tings) }\end{array}$ & $\begin{array}{l}\text { Optimal assortment compo- } \\
\text { sition of manufactured toy } \\
\text { sets })\end{array}$ & $\begin{array}{l}\text { Monthly profit [US\$] (value of } \\
\text { the objective function) }{ }^{*} \text { ) }\end{array}$ \\
\hline no limitations & $x_{1}=119 ; x_{2}=2, x_{3}=12, x_{9}=1$ & $2,205,22$ \\
\hline$x_{1}=0$ & $x_{3}=47$ & $1,929,59$ \\
\hline$x_{1} \leq 20 ; x_{2} \leq 20 ; x_{3} \leq 20 ;$ & $\begin{array}{l}x_{1}=19 ; x_{2}=19, x_{3}=20, x_{9} \\
=10\end{array}$ & $1,899,64$ \\
\hline$x_{1} \leq 3 ; x_{2} \leq 3 ; x_{3} \leq 3 ; x_{9} \leq 3 ; x_{10} \leq 2 ;$ & $\begin{array}{l}x_{1}=3 ; x_{2}=3 ; x_{3}=3 ; x_{9}=3 ; \\
x_{10}=2 ; \\
x_{4} \leq 2 ; x_{11} \leq 2 ; x_{6} \leq 2 ; x_{5} \leq 2\end{array}$ & $1,339,96$ \\
\hline
\end{tabular}

\section{CONCLUSIONS}

In this research paper, a multi-stage design framework for planning near-optimal process layouts in discrete parts manufacture was outlined, as based on the hierarchical clustering of processing routings for a res- 
pective part spectrum. It has been applied to production rationalisation by the reduction of ineffective material flows and related losses within an existing wood processing plant involved in the manufacture of wooden construction sets. Furthermore, given data sets derived from the real industrial case, the associated analysis of generated workflows in the manufacturing facility was carried out to determine the impact of production bottlenecks in generated baseline process layout. The impact of the bottleneck has been offset by the duplicating the bottleneck resource. However, no shift in the bottleneck location could be observed for the layout with doubled machine, revealed in prior as a bottleneck resource in the baseline layout. This was caused by significant differences in the work load of this machine compared to other machines. The linear programming model has been proven to be an effective tool for selecting the optimum range of multi-element product sets to be manufactured in specific time horizons. As it could be further found, controlling the selection of the optimal assortment composition in a definite time frame was enabled by formulating additional constraints related to the quantities of selected product items.

To sum it up, this research study proves the usefulness of the concept, and the entire methodical scheme can be used as a basic idea in planning the manufacture of modular sets of furniture as well as other multi-element wooden constructions. Further research should mostly focus on the implementation of the mechanism for decision making based on methods of intelligent reasoning involving in particular the use of fuzzy logic.

\section{ACKNOWLEDGEMENTS}

Part of this work was carried out under the CEEPUS III Mobility Program Network No. CIII-SK-0310-09-1617. The authors wish to thank Professor Kazimierz A. Orłowski from Gdansk University of Technology for inspiring advice and the encouragement. Special thanks are to the company of Kusing Trade, s.r.o. (Slovakia) for providing product- and industrial data utilised in experiments.

\section{REFERENCES}

Alvarez, P.P.; Vera, J.R. 2014. Application of robust optimization to the sawmill planning problem. Annals of Operations Research 219(1): 457-475.

Barni, A.; Corti, D.; Pedrazzoli, P.; Rovere, D.; Lucisano, G. 2017. Mini-factories for close-to-customer manufacturing of customized furniture: from concept to real demo. Procedia Manufacturing 11: 854-862.

Belleville, B.; Ashley, P.; Ozarska, B. 2016. Wood machining properties of Australian plantation-grown Eucalypts. Maderas. Ciencia y tecnologia 18(4): 677-688.

Dell Statistica $^{\circledR}$. 2016. Data analysis software system, ver.13. Dell Inc., $<$ https://boomi.com/wp-content/ uploads/MSA-Boomi-Master-Services-Agreement-06.25.18-4.pdf >

Ebner, M.; Petutschnigg, A.J. 2007. Potentials of thermally modified beech (Fagus sylvatica) wood for application in toy construction and design. Materials and Design 28(6): 1753-1759.

Esmaeilian, B.; Behdad, S.; Wang, B. 2016. The evolution and future of manufacturing: a review. Journal of Manufacturing Systems 39: 79-100.

Friso, V.R.; Silva, J.C.R.P.; Landim, P.C.; Paschoarelli, L.C. 2015. Ergonomic analysis of visual and tactile information of materials used in the manufacture of toys. Procedia Manufacturing 3: 6161-6168.

Gould, O.; Colwill, J. 2015. A framework for material flow assessment in manufacturing systems. Journal of Industrial and Production Engineering 32(1): 55-66.

Goyal, K.K., Jain. P.K., Jain, M. 2013. A comprehensive approach to operation sequence similarity based part family formation in the reconfigurable manufacturing system. International Journal of Production Research 51(6): 1762-1776. 
IBM ILOG ${ }^{\circledR}$ CPLEX®. 2016. IBM ILOG ${ }^{\circledR}$ CPLEX ${ }^{\circledR}$ Optimization Studio ver.12.7, IBM Academic Initiative $2016<$ https://ibm.onthehub.com/WebStore/ProductSearchOfferingList.aspx?srch=Cplex $>\quad$ (access 04.12.2017)

Irani, S.A.; Huang, H. 2005. Cascading flowlines and layout modules: Practical strategies for machine duplication in facility layouts. International Journal of Flexible Manufacturing Systems 17(2): 119-149.

Krajcovicova, M. 2011. Determination of bottlenecks in the production of wooden constructions. Drewno 54 (186): 65-73.

Longo, F.; Mirabelli, G.; Papoff, E. 2006. Material flow analysis and plant lay-out optimization of a manufacturing system. International Journal of Computing 5(1): 107-116.

Moraga, M.; Baesler F.F. 2001. The use of artificial intelligence for the optimization of a simulation model applied to a radiate pine manufacturing process. Maderas. Ciencia y tecnologia 3(1-2): 55-62.

Nakkiew, W.; Poolperm, P. 2016. Application of material flow cost accounting (MFCA) and quality control tools in wooden toys product. Intl. Conference on Industrial Engineering and Operations Management, Kuala Lumpur, Malaysia, March 2016: 801-812.

Nyemba, W.R.; Mbohwa, Ch. 2017a. Modelling, simulation and optimization of the materials flow of a multi-product assembling plant. Procedia Manufacturing 8: 59-66.

Nyemba, W.R.; Mbohwa, Ch. 2017b. Process mapping and optimization of the process flows of a furniture manufacturing company in Zimbabwe using machine distance matrices. Procedia Manufacturing 8: 447-454.

Opacic, L.; Sowlati, T. 2017. Applications of discrete-event simulation in the forest products sector: a review. Forest Products Journal 67(3-4): 219-229.

Orlowski, K.; Walichnowski, A. 2013. Analiza ekonomiczna produkcji warstw licowych podłóg klejonych warstwowo (in Polish). Economic analysis of upper layer production of engineered floorings. Drewno 56 (189): 115-126.

Preactor APS ${ }^{\circledR}$. 2009. Production planning and scheduling software system, ver. 9.5. Preactor International Ltd., Available online <www.preactor.com/Home.aspx> (accessed on: 03. December 2017).

Rahman, A.; Yella, S.; Dougherty, M. 2014. Simulation and optimization techniques for sawmill yard operation - a literature review. Journal of Intelligent Learning Systems and Applications 6(2): 21-34.

Siemiatkowski, M. 2010. Application of syntactic pattern recognition approach in design and optimisation of group machining systems. Solid State Phenomena Journal 165, Trans. Tech. Publications Inc: 342-347.

Siemiatkowski, M.; Przybylski, W. 2006. Simulation studies of process flow with in-line part inspection in machining cells. Journal of Materials Processing Technology 171(1): 27-34.

Stump, B.; Badurdeen, F. 2012. Integrating lean and other strategies for mass customization manufacturing: a case study. Journal of Intelligent Manufacturing 23(1):109-124. Press.

Sultan, A. 1993. Linear programming: An introduction with applications. San Diego, CA: Academic

Teischinger, A. 2010. The development of wood technology and technology developments in the wood industries - from history to future. European Journal of Wood and Wood Products 68(3): 281-287.

Thoews, S.E.; Maness, T.C.; Ristea, C. 2008. Using flow simulation as a decision tool for improvements in sawmill productivity. Maderas-Cienc Tecnol 10(3): 229-242.

Thomas, P.; Suhner, M.Ch.; Thomas, A. 2015. Reduced simulation model for flow analysis in a sawmill internal supply chain. Intl. Conference on Industrial Engineering and Systems Management, IESM'15, Seville, Oct 2015: 1-10. 
Wood Handbook. 2010. Wood Handbook. Wood as an engineering material. Centennial Edition. US Department of Agriculture Forest Service. Forests Product Laboratory: Madison, Wisconsin.

Yin, Y.; Yasuda, K. 2006. Similarity coefficient methods applied to cell formation problem: A taxonomy and review. International Journal of Production Economics 101(2): 329-352. 